\title{
SARS-CoV-2 are drying-resistant and cause droplet nuclei transmission
}

\author{
Daisuke Miyazawa ${ }^{1}$ \\ ${ }^{1}$ Affiliation not available
}

July 29, 2020

Droplet nuclei are sometimes defined only by size. The Centers for Disease Control and Prevention (CDC) defines that "droplet nuclei are dried residue of less than 5 microns in size" (1) . But it is sometimes explained as: "Small drops of moisture carrying infectious pathogens are called droplet nuclei" (2). World Health Organization (WHO) defines that "when the droplet particles are $>5-10 \mu \mathrm{m}$ in diameter they are referred to as respiratory droplets, and when then are $<5 \mu \mathrm{m}$ in diameter, they are referred to as droplet nuclei" (3) ,not requiring desiccation..

The term droplet nuclei needs to be clearly defined in terms of desiccation. For the purposes of this article, droplet nuclei will be discussed using the CDC's definition of droplet nuclei with a requirement for desiccation. The WHO and CDC's current position is based on the conventional medical definition that in human exhalation origin, only droplet nuclei can cause airborne transmittion (1) . To date, WHO and CDC suspects but do not officially recognize airborne SARS-CoV-2 transmission (4). The viruses that the CDC is currently warning about as causing airborne transmission are limited to measles, chickenpox, disseminated shingles, and smallpox(5). Other viruses are suspected but not confirmed. Suspected case of SARS-CoV transmission via apartment building air (6), outbreaks of influenza in an airplane delayed on the ground with inoperative ventilation system (7), and reports of simultaneous COVID-19 outbreaks in large enclosed spaces (8), suggest that all these enveloped viruses are transmitted by dry droplet nuclei, because it is unlikely that the fine droplets will stay moist for such long distances and time. Wells found that droplets smaller than $100 \mu \mathrm{m}$ would completely dry out before falling approximately $2 \mathrm{~m}$ to the ground(9).

Morawska calculated that "droplets with sizes of the order of $1 \mu \mathrm{m}$ evaporate within a few milliseconds, even under the conditions of high relative humidity. Droplets of the order of $10 \mu \mathrm{m}$ exist for up to a few tens of a second, while very large droplets, $100 \mu \mathrm{m}$ in diameter, survive for up to almost a minute" (10) . SARS-CoV-2 and SARS-CoV exhibited similar half-lives in aerosols, with median estimates around 2.7 hours (11) . In this study, all aerosols should have dried out during the course of the process and turned into droplet nuclei. A couple of hours of half-life time should be sufficient for the dry droplet nuclei to be dispersed and become clinically infectious especially in an enclosed environment. The presence of infectious, replicating virions in $<1 \mu \mathrm{m}$ aerosol samples have been shown by showing increases in viral RNA during cell culture of the virus from aerosol samples (12). As it has been calculated that droplets with sizes of the order of $1 \mu \mathrm{m}$ evaporate within a few milliseconds(10), it indicates that SAS-CoV-2 can cause droplet nuclei transmittion. SARS-CoV-2 has been shown not to be inactivated on plastic and stainless steel for a couple of days (11) . Generally, enveloped viruses which has lipid envelope tend to be more persistent at lower relative humidity, while nonenveloped are more stable at higher relative humidities (13).

Airborne transmission is meant by most authors to be synonymous with aerosol transmission (14). WHO states as follows: "Airborne transmission is defined as the spread of an infectious agent caused by the dissemination of droplet nuclei (aerosols) that remain infectious when suspended in air over long distances and time" (7). This statement includes two definitions. First, WHO define that the term "airborne transmission" 
is limited to transmission by droplet nuclei. Second, WHO define that airborne, droplet nuclei, and aerosol transmission are all synonymous. CDC states that "The definition of an aerosol, as used here, is a suspension of tiny particles or droplets in the air, such as dusts, mists, or fumes." (15). CDC's definition requires droplet nuclei to be dry, and airborne transmission is limited to transmission by droplet nuclei.

Therefore, aerosol transmission is not synonymous to airborne or droplet nuclei transmission in CDC's definition. Additionally, in most reports stating SARS-CoV-2 is airborne and/or aerosol-transmitted, the definitions of the terms airborne and aerosol are not clear whether those refer only to dry droplet nuclei or it includes fine, moist droplets floating in the air (14).

The fact that the definitions of aerosols and droplet nuclei are not uniform worldwide, even between the WHO and CDC, is a huge detriment

Indeed, it is difficult to determine how small and how dry a particle is to be called a droplet or droplet nuclei. If the vagueness of this boundary is a problem, the alternative is to abolish the classification of droplets and droplet nuclei and reclassify them as droplets and aerosols, based solely on how much they are suspended in the air, regardless of how dry they are.

Along with the global unification of the definitions of aerosols and droplet nuclei, the above theoretical evidence showing that SARS-CoV-2 are drying-resistant and likely to be airborne transmitted by dry droplet nuclei, should be recognized.

\section{Refernces}

1. U.S. Department of Health \& Human Services. (2012, May 18). Principles of Epidemiology. Retrieved July 28, 2020, from https://www.cdc.gov/csels/dsepd/ss1978/lesson1/section10.html

2. Medical Advisory Secretariat. Air cleaning technologies: an evidence-based analysis. Ont Health Technol Assess Ser . 2005;5(17):1-52.

3. Modes of transmission of virus causing COVID-19: implications for IPC precaution recommendations. World Health Organization. https://www.who.int/news-room/commentaries/detail/modesof-transmission-of-virus-causing-covid-19-implications-for-ipc-precaution-recommendations. Published July 9, 2020. Accessed July 29, 2020.

4. Morawska L, Milton DK. It is Time to Address Airborne Transmission of COVID-19 [published online ahead of print, $2020 \mathrm{Jul} 6$ 6. Clin Infect Dis . 2020;ciaa939. doi:10.1093/cid/ciaa939

5. Isolation Precautions. https://www.cdc.gov/infectioncontrol/guidelines/isolation/index.html. Published July 22, 2019. Accessed July 28, 2020.

6. Yu IT, Li Y, Wong TW, et al. Evidence of airborne transmission of the severe acute respiratory syndrome virus. $N$ Engl $J$ Med . 2004;350(17):1731-1739. doi:10.1056/NEJMoa032867

7. Moser MR, Bender TR, Margolis HS, Noble GR, Kendal AP, Ritter DG. An outbreak of influenza aboard a commercial airliner. Am J Epidemiol . 1979;110(1):1-6. doi:10.1093/oxfordjournals.aje.a112781

8. Transmission of SARS-CoV-2: implications for infection prevention precautions. World Health Organization. https://www.who.int/news-room/commentaries/detail/transmission-of-sarscov-2-implications-for-infection-prevention-precautions. Published 2020. Accessed July 28, 2020.

9. Atkinson J, Chartier Y, Pessoa-Silva CL, et al., editors. Natural Ventilation for Infection Control in Health-Care Settings. Geneva: World Health Organization; 2009. Annex C, Respiratory droplets. Available from:https://www.ncbi.nlm.nih.gov/books/NBK143281/

10. Morawska L. Droplet fate in indoor environments, or can we prevent the spread of infection?. Indoor Air . 2006;16(5):335-347. doi:10.1111/j.1600-0668.2006.00432.x

11. van Doremalen N, Bushmaker T, Morris DH, et al. Aerosol and Surface Stability of SARS-CoV-2 as Compared with SARS-CoV-1. N Engl J Med . 2020;382(16):1564-1567. doi:10.1056/NEJMc2004973

12. Santarpia JL, Herrera VL, Rivera DN, et al. The Infectious Nature of Patient-Generated SARS-CoV-2 Aerosol medRxiv 2020.07.13.20041632; doi: https://doi.org/10.1101/2020.07.13.20041632

13. Sobsey, M.D. and Meschke, J.S., 2003. Virus survival in the environment with special attention to 
survival in sewage droplets and other environmental media of fecal or respiratory origin. Report for the World Health Organization, Geneva, Switzerland

14. Tellier R, Li Y, Cowling BJ, Tang JW. Recognition of aerosol transmission of infectious agents: a commentary. BMC Infect Dis . 2019;19(1):101. Published 2019 Jan 31. doi:10.1186/s12879-019-3707$\mathrm{y}$

15. Aerosols. Centers for Disease Control and Prevention. https://www.cdc.gov/niosh/topics/aerosols/default.html. Published June 29, 2010. Accessed July 29, 2020.

Keywords: Aerosol, Airborne, Droplet, nuclei, Transmission 